Research Article

\title{
Utilization of Machine Vision to Monitor the Dynamic Responses of Rice Leaf Morphology and Colour to Nitrogen, Phosphorus, and Potassium Deficiencies
}

\author{
Yuanyuan Sun $\mathbb{D}^{\mathbb{D}},{ }^{1}$ Jiali Gao $\mathbb{D}^{1},{ }^{1}$ Ke Wang $\mathbb{D},{ }^{1}$ Zhangquan Shen $\mathbb{D}^{1},{ }^{1}$ and Lisu Chen $\mathbb{D}{ }^{1,2}$ \\ ${ }^{1}$ Institute of Applied Remote Sensing and Information Technology, College of Environmental and Resource Sciences, \\ Zhejiang University, Hangzhou, Zhejiang, China \\ ${ }^{2}$ College of Ocean Science and Engineering, Shanghai Maritime University, Shanghai, China
}

Correspondence should be addressed to Ke Wang; kwang@zju.edu.cn and Lisu Chen; cls512@zju.edu.cn

Received 19 January 2018; Revised 14 April 2018; Accepted 17 April 2018; Published 3 July 2018

Academic Editor: Andras Gorzsas

Copyright ( 2018 Yuanyuan Sun et al. This is an open access article distributed under the Creative Commons Attribution License, which permits unrestricted use, distribution, and reproduction in any medium, provided the original work is properly cited.

Machine vision technology enables the continuous and nondestructive monitoring of leaf responses to different nutrient supplies and thereby contributes to the improvement of diagnostic effects. In this study, we analysed the temporal dynamics of rice leaf morphology and colour under different nitrogen $(\mathrm{N})$, phosphorus $(\mathrm{P})$, and potassium $(\mathrm{K})$ treatments by continuous imaging and further evaluated the effectiveness of dynamic characteristics for identification. The top four leaves (the 1st incomplete leaf and the top three fully expanded leaves) were scanned every three days, and all images were processed in MATLAB to extract the morphological and colour characteristics for dynamic analysis. Subsequently, the mean impact value was applied to evaluate the effectiveness of dynamic indices for identification. According to the results, higher nutrient supply resulted in a faster leaf extension rate and a lower developing rate of chlorosis, and the influence of $\mathrm{N}$ deficiency on leaf growth was the greatest, followed by $\mathrm{P}$ deficiency and then $\mathrm{K}$ deficiency. Furthermore, the optimal indices for identification were mainly calculated from morphological characteristics of the 1st incomplete leaf and colour characteristics of the 3rd fully expanded leaf. Overall, dynamic analysis contributes not only to the exploration of the plant growth mechanism but also to the improvement of diagnostics.

\section{Introduction}

Nitrogen $(\mathrm{N})$, phosphorus $(\mathrm{P})$, and potassium $(\mathrm{K})$ are the three main macronutrients for rice growth $[1,2]$. However, due to the lack of real-time and accurate nutrition diagnosis in the field, farmers tend to overuse fertilizer in order to achieve high yield, which can lead to environmental problems and waste of resources. Therefore, nondestructive, timely, and precise NPK nutrition diagnosis is needed in field management to improve crop yield and agricultural sustainability.

In recent years, hyperspectral imaging technology has received tremendous attention in several research fields. This technology integrates both spectral and morphological information that has been successfully applied in nutrition diagnosis [3-5], water content estimation [6, 7], mapping of the distribution of plant nutrition $[3,8]$, and fruit injury detection [9]. However, the high cost and complex operation of the equipment limit the popularization and application of this technology in the field $[10,11]$. Alternatively, digital images acquired by digital cameras or scanners contain abundant information about colour, morphology, and texture features [11-13], which are easy to obtain with existing software. Moreover, the effectiveness of digital images in nutrition diagnosis has been proved in numerous studies [11, 13-15]. Compared to hyperspectral imaging technology, digital image processing technology has the advantages of low cost, simple operation, and good portability in practical applications.

However, current studies mainly focus on plant information at certain major growth stages [11, 16-18]; this intermittent information collected with long sampling intervals is incomplete, and some important information may be ignored. Leaf chlorosis, an important trait for nitrogen diagnosis, is traditionally measured by assessing leaf colour at a certain stage [19], but the development of chlorosis, 
which carries valuable information, is difficult to quantify with intermittent information. In addition, nutrition diagnosis based on digital images mainly relies on the significant symptoms caused by nutrient deficiency. To some extent, this dependence on the appearance of characteristic symptoms delays the nutrition diagnosis $[14,20]$. It is observed that plant responses to nutrient deficiency are embodied not only in the symptoms but also in the formation and development of these symptoms. Therefore, a complete analysis of plant dynamics will contribute to the early diagnosis. Given the above, continuous monitoring with a small sampling interval is particularly necessary for the exploration of valuable information and the improvement of diagnostic effects.

Based on plant physiology, nutrient deficiency exerts influence throughout the life cycle [21]. The leaf responses to different nutrient supplies would be distinct and are embodied in all stages of leaf life. In this context, the complete leaf responses can be captured in detail by continuous monitoring, enabling the further identification of sensitive characteristics, which is helpful for more-targeted collection of plant information in subsequent work. Moreover, obtaining the complete leaf responses allows the exploration of the diagnostic effects at any stage, which is also helpful for achieving satisfactory diagnoses as early as possible.

Recently, continuous monitoring has been applied in numerous studies to study the phenotypic responses of plants to various environmental conditions [22-24]. Studies conducted by Poire et al. [22], Neilson et al. [23], and Yong-hui et al. [25] reported the temporal dynamics of leaf morphology and colour during the leaf extension stage. Their results also showed that different nutrient supplies resulted in various dynamic characteristics (such as the leaf extension rates and rates of colour change), which indicated that nutrient deficiency could be identified by dynamic characteristics at early stages. In addition to the dynamic nature of leaf extension, the dynamics of other stages, such as chlorosis, which is a typical process of leaf growth when exposed to NPK deficiency, are also valuable for dynamic analysis. Therefore, continuous monitoring should be carried out in different leaf positions to analyse the dynamic natures of different leaf growth stages.

Given the above, dynamic analysis of leaf morphology and colour not only contributes to the further exploration of sensitive characteristics but also provides new ideas and methods for nutrition diagnosis. In this study, we aim to (1) explore the dynamic responses of leaf morphology and colour to NPK deficiencies using the 1st incomplete leaf and fully expanded leaves and (2) evaluate the effectiveness of dynamic indices in nutrition diagnosis, laying a foundation to identify NPK deficiencies.

\section{Materials and Methods}

2.1. Experimental Design. Rice plants (ZheYou-NO.1) were cultivated hydroponically under different NPK supplies. ZheYou-NO.1 is hybrid late indica rice that is cultivated by the China National Rice Research Institute and that was recommended by the Chinese Ministry of Agriculture for the farmers of East China. After three days of germination and 15 days of growth, the rice seedlings were transplanted to $5 \mathrm{~L}$ polyvinyl chloride (PVC) pots that contained NPK nutrient solution with various levels of nutrients. In 2014 and 2015, the experiment was carried out in a greenhouse on the ZiJinGang Campus of Zhejiang University ( $\left.30^{\circ} 17^{\prime} \mathrm{N}, 120^{\circ} 05^{\prime} \mathrm{E}\right)$ in Hangzhou, China. Rice plants were grown under natural light conditions. Nutrient solution formula from the International Rice Research Institute (IRRI) was used to cultivate the rice plants and was replaced every 15 days. Four kinds of nutrient treatments, $\mathrm{N}$ deficiency, $\mathrm{P}$ deficiency, $\mathrm{K}$ deficiency, and normal supply, were established in this experiment. There were four levels of nutrient application (extreme deficiency, severe deficiency, moderate deficiency, and mild deficiency) in each type of deficiency treatment: $\mathrm{N} 1-\mathrm{N} 4\left(\mathrm{NH}_{4} \mathrm{NO}_{3}: 0 \mathrm{mg} / \mathrm{L}, 28.60 \mathrm{mg} / \mathrm{L}\right.$, $57.20 \mathrm{mg} / \mathrm{L}, 85.70 \mathrm{mg} / \mathrm{L}) ; \mathrm{P} 1-\mathrm{P} 4\left(\mathrm{NaH}_{2} \mathrm{PO}_{4} .2 \mathrm{H}_{2} \mathrm{O}: 0 \mathrm{mg} / \mathrm{L}\right.$, $12.60 \mathrm{mg} / \mathrm{L}, \quad 25.20 \mathrm{mg} / \mathrm{L}, \quad 37.80 \mathrm{mg} / \mathrm{L}) ; \mathrm{K} 1-\mathrm{K} 4 \quad\left(\mathrm{~K}_{2} \mathrm{SO}_{4}\right.$ : $0 \mathrm{mg} / \mathrm{L}, 22.30 \mathrm{mg} / \mathrm{L}, 44.70 \mathrm{mg} / \mathrm{L}, 67.00 \mathrm{mg} / \mathrm{L}$ ); and normal supply $\left(\mathrm{NH}_{4} \mathrm{NO}_{3}: 114.30 \mathrm{mg} / \mathrm{L}, \mathrm{NaH}_{2} \mathrm{PO}_{4} \cdot 2 \mathrm{H}_{2} \mathrm{O}: 50.40 \mathrm{mg} / \mathrm{L}\right.$, $\mathrm{K}_{2} \mathrm{SO}_{4}: 89.30 \mathrm{mg} / \mathrm{L}$ ). In total, this trial was designed with thirteen nutrient levels with five replicates per level. Every 5 days, the $\mathrm{pH}$ of the nutrient solution in each pot was measured and adjusted to 5.5-6.5 using $1 \mathrm{~mol} \cdot \mathrm{L}^{-1} \mathrm{NaOH}$.

\subsection{Image Acquisition and Processing. Compared to a digital} camera, a scanner has advantages in image acquisition. Because scanning is performed in a closed environment, the effects of the external environment and operator error can be eliminated $[19,26]$. During data acquisition, rice leaves were scanned (EPSON GT20000) every 3 days from 20 days after the seedlings were transplanted (DAT20) to DAT44 in both 2014 and 2015. The top four leaves (the 1st incomplete leaf and the 1st, 2nd, and 3rd fully expanded leaves) of each plant were scanned at sampling times, and the experiments were conducted 9 times. All the scanned images were saved in the tag image file format (TIFF), and the scanned image size was $5100 \times 3510$ pixels.

The scanned leaf images were processed in MATLAB 2013b (MathWorks Inc., USA). The mean value and regionprops functions, which are provided by MATLAB, were applied to extract and quantify the characteristics of leaf colour and morphology. The mean value function was used to calculate the average value of objects, and the regionprops function can quantify the morphological properties of image such as area, perimeter, and circularity.

Since the leaf morphological characteristics were initially described in terms of pixels, we performed conversions to obtain the actual results (in centimetres). The resolution of scanned images was set to 300 dots per inch (dpi), where a dot is equivalent to a pixel. Because one inch equals $2.54 \mathrm{~cm}$, the length of one pixel was $2.54 / 300 \mathrm{~cm}$. Accordingly, the actual area $\left(\mathrm{cm}^{2}\right)$ was calculated as the sum of all pixels within the leaf range multiplied by $(2.54 / 300)^{2}$, and the actual perimeter $(\mathrm{cm})$, leaf length $(\mathrm{cm})$, and width $(\mathrm{cm})$ were calculated by multiplying the pixel number by $2.54 / 300$.

2.3. Dynamic Analysis of Leaf Morphology and Colour. In this paper, the top four leaves were classified into two main categories according to leaf growth status: the 1st incomplete leaf and fully expanded leaves (the 1st, 2nd, and 3rd fully expanded leaves). Dynamic analysis was carried out for the above two categories. 


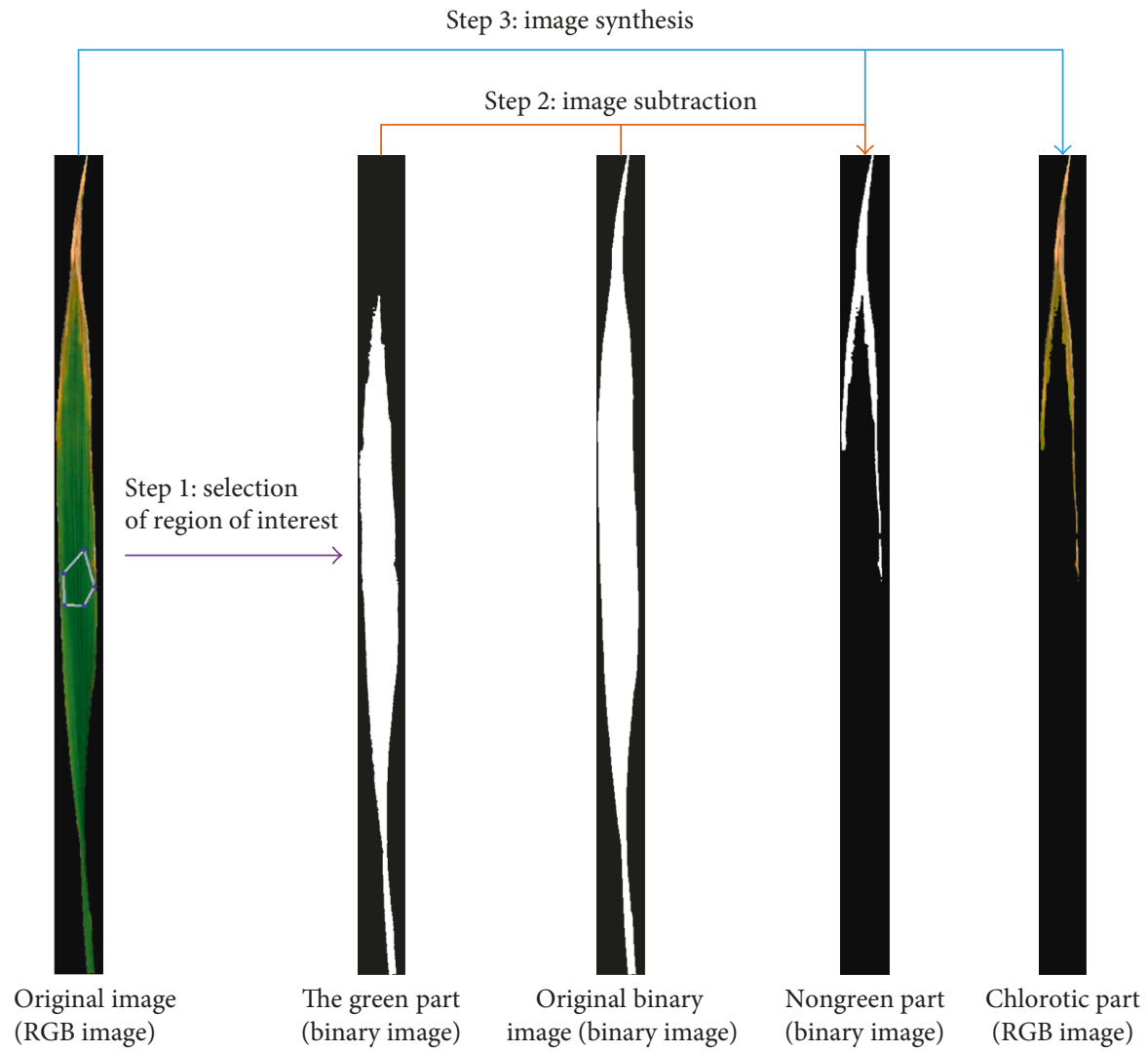

FIgURE 1: Segmentation of the chlorotic part of a rice leaf.

To illuminate the temporal dynamics of rice leaf at different stages, the 1st incomplete leaf was used to elucidate the leaf dynamics from emergence to fully expanded, and the fully expanded leaves were used in analysis of leaf dynamics from fully expanded to fully withered. To analyse the dynamic characteristics of rice leaf, we started with the morphology and colour characteristics. Among the various leaf morphological characteristics, the leaf area provides more comprehensive leaf information that is suitable to reveal the dynamic nature of leaf extension. In addition, the normalized red index (NRI), which has been proved to be closely related to plant nutrition $[27,28]$, is chosen to describe the dynamic changes of leaf colour.

Furthermore, leaf chlorosis is a typical symptom resulting from NPK deficiency; the more severe the deficiency is, the greater the chlorosis rate. Therefore, to further explore the leaf responses to NPK deficiencies, we segmented the chlorotic part to reveal the development of leaf chlorosis. To carry out the segmentation, the "colorseg" function, which was defined by Gonzalez [29], was applied in MATLAB.

The specific segmentation procedure, as presented in Figure 1, was as follows: the green part of the leaf was first extracted by the selection of a region of interest (ROI), followed by image subtraction between the entire leaf and the green part (both of them converted to binary images during image segmentation) to extract the nongreen (chlorotic) part. Finally, we used image synthesis to restore the original colour characteristics of the chlorotic part for the subsequent analysis. In this paper, we selected the green part rather than the chlorotic part as the ROI (region of interest) in segmentation because the chlorotic part was small at the beginning of the leaf chlorosis, and its spatial heterogeneity was higher than that of the green part, making it difficult to select a representative region of interest for complete segmentation.

Moreover, we used the chlorosis rate to analyse the development of leaf chlorosis in the NPK treatments. Compared to the chlorotic area, the chlorosis rate eliminates the influence of leaf size and more accurately reveals the process of leaf chlorosis. The chlorosis rate was calculated according to the following formula:

$$
\text { chlorosis rate }=\frac{\text { chlorotic area }}{\text { leaf area }} \text {. }
$$

In addition, the above characteristics of the four nutrition levels in each treatment (except the normal treatment) were averaged for further comparison between different treatments.

\subsection{Potential Evaluation of Dynamic Indices for Nutrition} Diagnosis. The leaf responses differed based on the nutrient deficiencies to which they were exposed, and those differences varied with time. Therefore, to identify the optimal characteristics and the appropriate diagnostic time, leaf dynamics were quantified at various time points and further used in potential evaluation.

2.4.1. Quantification of Dynamic Characteristics. Relative growth rate (RGR) is an essential parameter to evaluate plant growth rate and is widely used in botany studies [22, 23]. In this 
TABle 1: Indices calculated from different leaf characteristics.

\begin{tabular}{|c|c|c|}
\hline Category & Index & Formula \\
\hline \multirow{4}{*}{ Morphological indices } & Leaf width (LW) & \\
\hline & Leaf length (LL) & \\
\hline & Leaf area (LA or CLA) & \\
\hline & Leaf perimeter (LP) & \\
\hline \multirow{10}{*}{ Colour indices } & Red (R or CR) & \\
\hline & Green (G or $C G)$ & \\
\hline & Normalized red index (NRI) & $N R I=R /(R+G+B)$ \\
\hline & Normalized green index (NGI) & $\mathrm{NGI}=\mathrm{G} /(\mathrm{R}+\mathrm{G}+\mathrm{B})$ \\
\hline & Dark green colour index (DGCI) & $\begin{aligned} \text { DGCI }= & \{(\text { hue }-60) / 60+(1-\text { saturation }) \\
& +(1-\text { brightness })\} / 3\end{aligned}$ \\
\hline & Excess green vegetation index $(\mathrm{ExG})$ & $E x G=2 N G I-N R I-N B I$ \\
\hline & Excess green minus excess red (ExGR) & $\mathrm{ExGR}=\mathrm{ExG}-\mathrm{ExR}$ \\
\hline & Green-red vegetation index (GRVI) & $\mathrm{GRVI}=(\mathrm{G}-\mathrm{R}) /(\mathrm{G}+\mathrm{R})$ \\
\hline & Kawashima index $\left(\mathrm{I}_{\mathrm{KAW}}\right)$ & $\mathrm{I}_{\mathrm{KAW}}=(\mathrm{R}-\mathrm{B}) /(\mathrm{R}+\mathrm{B})$ \\
\hline & Principal component analysis index $\left(\mathrm{I}_{\mathrm{PCA}}\right)$ & $\mathrm{I}_{\mathrm{PCA}}=0.994|\mathrm{R}-\mathrm{B}|+0.961|\mathrm{G}-\mathrm{B}|+0.914|\mathrm{G}-\mathrm{R}|$ \\
\hline
\end{tabular}

CLA, CR, and CG represent the LA, R, and G of the chlorotic part, respectively.

paper, we expanded the application of RGR in plant biomass to leaf morphology and colour indices (Table 1) to quantify leaf dynamics. RGR was calculated according to Hunt [30]:

$$
\mathrm{RGR}=\frac{(\ln W 2-\ln W 1)}{(t 2-t 1)},
$$

where $W 1$ and $W 2$ are the initial and final values at the beginning $(t 1)$ and the end $(t 2)$ of the measurement period, respectively (2).

The RGR was calculated from DAT20 to DAT44 in both 2014 and 2015, with the time interval between $t 1$ and $t 2$ being set at 3 days. In total, there were 8 data sets. However, the data sets from the last time point were not utilized in this analysis because of the missing data due to leaf wilt. Therefore, 7 data sets, named P1 to P7, were used in the potential evaluation.

2.4.2. Potential Evaluation. The mean impact value (MIV) was used to evaluate the effectiveness of dynamic indices in identifying different kinds and levels of deficiencies. The MIV was calculated based on the BP (back propagation) neural network, and a higher absolute value of the MIV means that the dynamic indices are more effective for identification [31, 32].

\section{Results}

3.1. Dynamic Responses of the Area and Colour of the 1st Incomplete Leaf to NPK Deficiencies. According to plant growth mechanism, rice plants under NPK deficiency exhibit stunted growth and different leaf morphology. Meanwhile, leaves under $\mathrm{N}$ deficiency were light green in colour, while dark green leaves could be observed in plants under PK deficiency. To reveal the influence of NPK deficiency on rice growth and explore effective characteristics for nutrition diagnosis, analyses of leaf morphology and colour dynamics during leaf extension process were carried out in the 1st incomplete leaf.

3.1.1. The Increase in Leaf Area in Response to NPK Deficiencies. Detailed leaf extension process of the 1st incomplete leaf is shown in Figure 2. The growth curve showed vigorous growth during the first 6 days, after which the leaf growth rate decreased over time. Overall, it took approximately 10 days to reach the peak leaf area.

Apparently, there was a strong treatment effect for leaf extension when rice plants were exposed to different levels of NPK deficiencies. As depicted in Figures 2(a)-2(c), leaf extension rate increased with the increasing nutrient supply, and higher nutrient supply resulted in bigger leaf area. To assess the different influences of NPK deficiencies, the average values of four nutrition levels in each treatment were calculated for further comparison. As depicted in Figure 2(d), leaves with normal nutrient supply exhibited the largest area and highest extension rate, followed by the $\mathrm{K}$ treatment, $\mathrm{P}$ treatment, and $\mathrm{N}$ treatment, in that order.

3.1.2. Dynamic Changes in Leaf Colour in Response to NPK Deficiencies. For all the treatments, a decreasing trend in NRI dynamics was observed during leaf extension, and NRI remained basically stable once rice leaves were fully expanded (Figure 3).

When exposed to NPK deficiency, different levels of nutrient supplies resulted in different colour variations. As depicted in Figures 3(a) and 3(b), the temporal dynamics of NRI differed among the four nutrition levels for the $\mathrm{N}$ and $\mathrm{P}$ treatments, with leaves with higher nutrient supply showing greater declines in NRI and stabilization at lower values. However, there were no significant differences between the four nutrition levels in the $\mathrm{K}$ treatment (Figure 3(c)). Moreover, Figure 3(d) shows further comparison of colour variations between the four treatments. Clearly, similar colour variations can be observed in the $\mathrm{K}$ and normal treatments, and their decreases in NRI during the leaf extension stage were the largest, followed by the $\mathrm{P}$ treatment and then the $\mathrm{N}$ treatment.

As displayed earlier, distinct changes in leaf characteristics could be observed among different nutrient supplies, which indicated that dynamic characteristics (changes in leaf morphology and colour) of the 1st incomplete leaf could be used to identify NPK deficiency. 


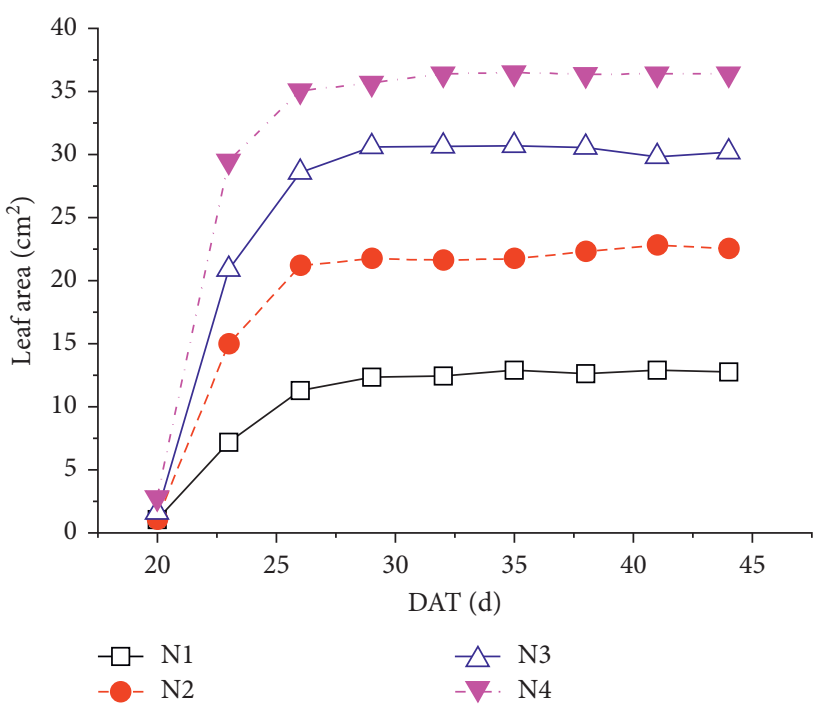

(a)

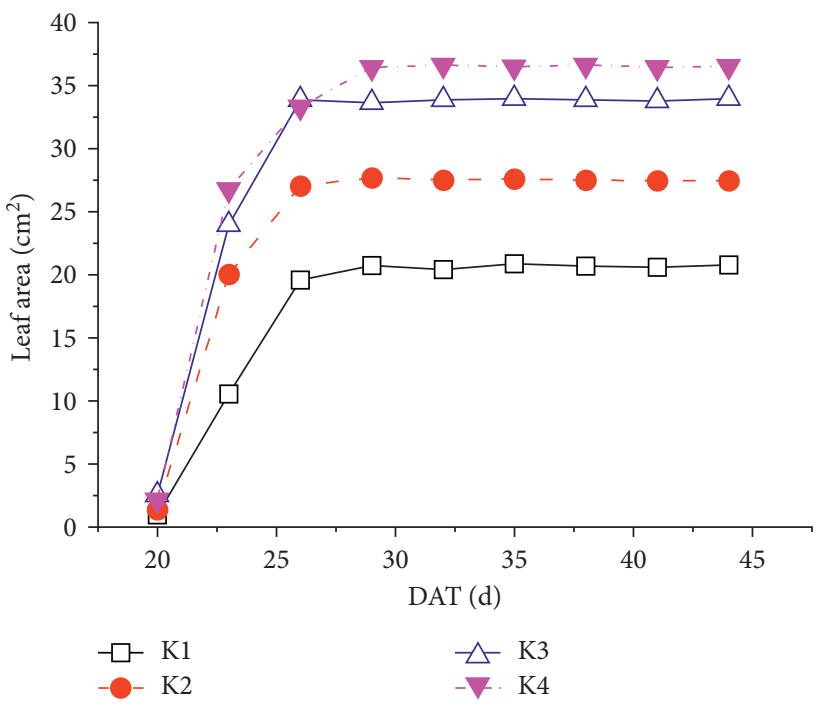

(c)

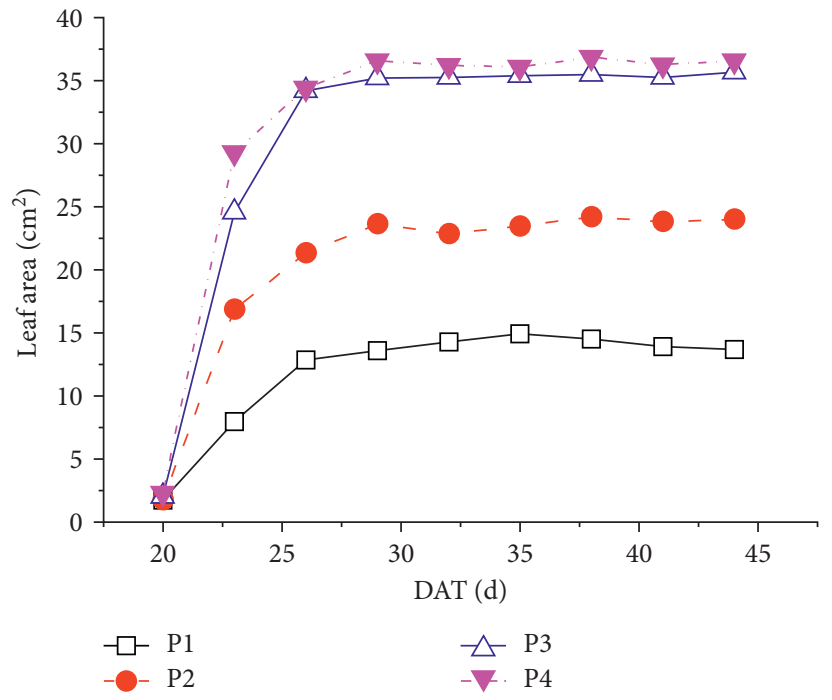

(b)

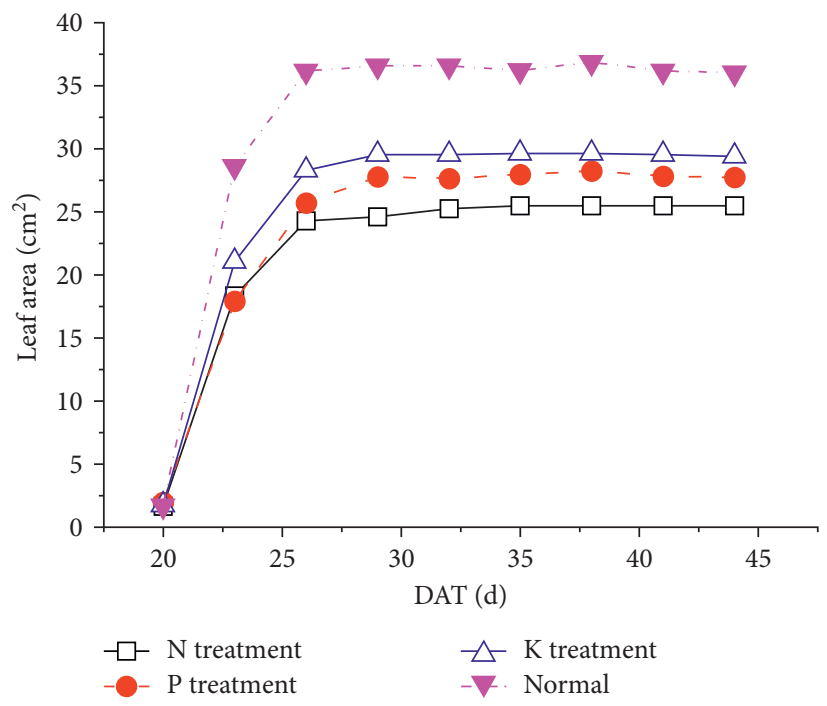

(d)

Figure 2: Dynamic responses of leaf area to different nutrient supplies: (a) N treatment, (b) P treatment, (c) K treatment, and (d) the overall changes in the N, P, K, and normal treatments (average values of the four nutrition levels in each treatment). DAT: day after transplantation.

3.2. Dynamic Area and Colour Responses of the Fully Expanded Leaves to NPK Deficiencies. It is widely accepted that deficiencies in NPK nutrition accelerate leaf senescence. Meanwhile, different symptoms could be observed in the fully expanded leaves when exposed to NPK deficiency: Under N deficiency, the entire leaf loses its green colour and gradually becomes yellow; under P deficiency, rice leaves become greypurple, and under $\mathrm{K}$ deficiency, rice leaves exhibit scorched margins and brown necrotic spots. The morphological and colour dynamics of the fully expanded leaves also differ with different nutrient supplies. Therefore, we explored the temporal dynamics of fully expanded leaves to reveal the influence of NPK deficiency and obtain effective information for nutrition diagnosis.

3.2.1. Dynamic Changes in Leaf Area in Response to NPK Deficiencies. As shown in Figure 4, the three fully expanded leaves displayed the progression from stability to senescence. Consequently, the leaf area declined over time and then remained stable when the rice leaf became fully withered. Moreover, the overall developing trends indicated that the largest changes in leaf area appeared first in the 3rd fully expanded leaf and then the 2nd fully expanded leaf, and there were no significant changes in the 1st fully expanded leaf.

Moreover, a strong treatment effect on leaf wilt could be observed among different nutrient supplies. For leaf responses between different levels of nutrient supply (Figures 4(a)-4(i)), the results indicated that the decrease in leaf area started earlier and ended earlier with lower nutrient supply. For leaf responses between different types of nutrient supply (Figures $4(\mathrm{j})-4(\mathrm{l})$ ), the leaves with NPK deficiencies withered earlier and faster than those with normal nutrient supply, and leaf wilt in the $\mathrm{N}$ treatments began earliest and developed with the fastest rate, followed by the $\mathrm{P}$ and $\mathrm{K}$ treatments. 

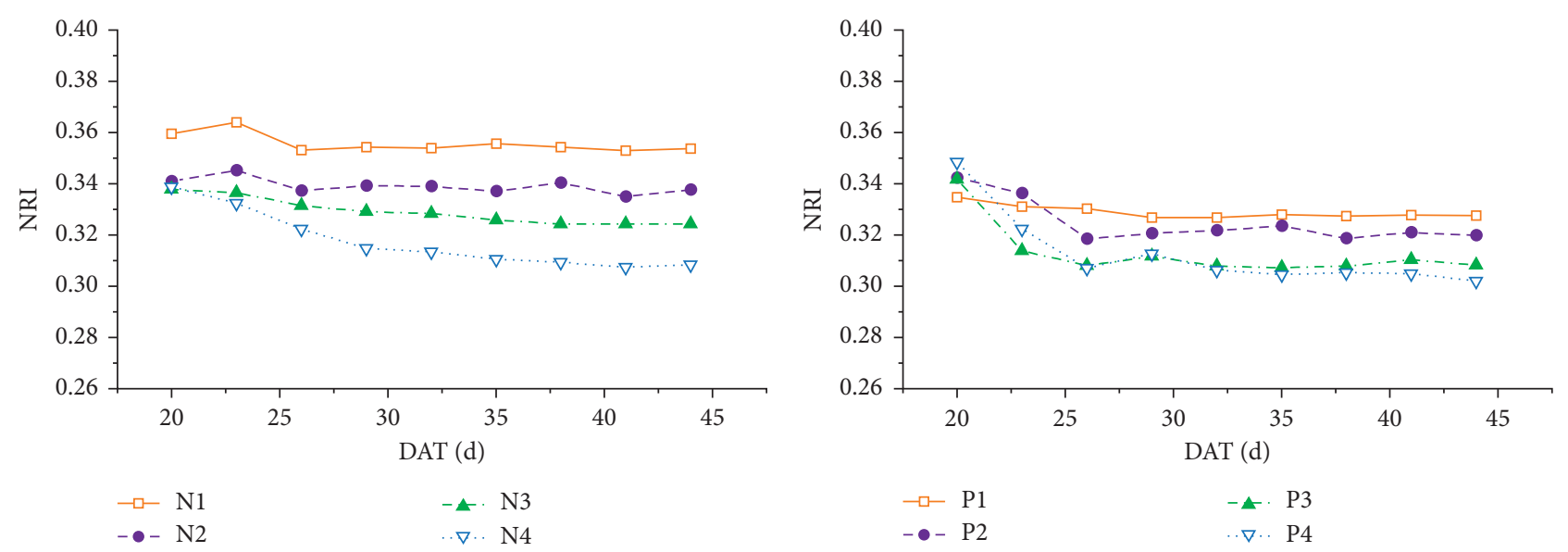

(a)
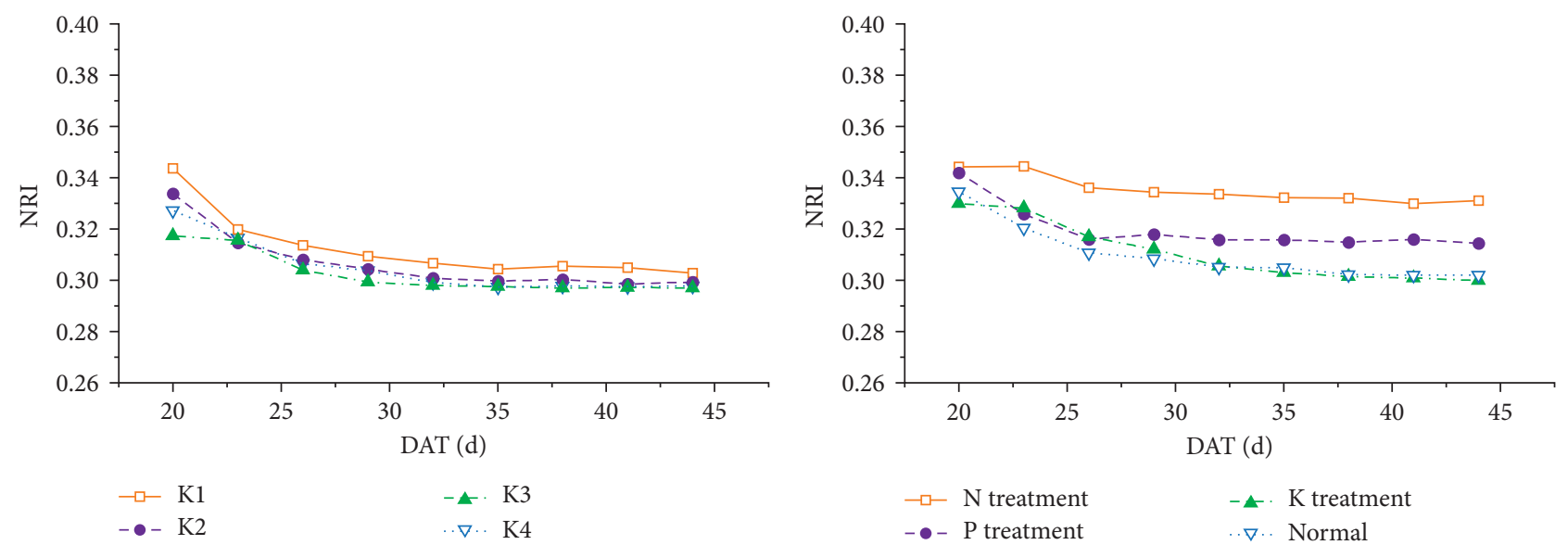

(c)

(d)

Figure 3: Dynamic responses of leaf colour to different NPK supplies: (a) N treatment, (b) P treatment, (c) K treatment, and (d) the overall changes in the N, P, K, and normal treatments (average values of the four nutrition levels in each treatment). DAT: day after transplantation.

3.2.2. Dynamic Changes in Leaf Colour in Response to NPK Deficiencies. As shown in Figure 5, NRI displayed an overall increasing trend in all treatments. When rice leaves became completely withered, NRI was maintained at a stable value that is called the "terminal point" in this article.

Similar to the leaf area dynamics, colour changes were most obvious in the 3rd fully expanded leaf, followed by the 2nd and then the 1st fully expanded leaves. Moreover, colour variation also differed with the nutrient supplies. Among the four nutrition levels in each treatment (Figures 5(a)-5(c)), NRI increased more quickly and reached the terminal point earlier when exposed to a lower nutrient supply. On the other hand, colour variations among the four nutrition treatments (Figure 5(d)) implied that leaves with $\mathrm{N}$ deficiency had higher NRI values than leaves in the other treatments, and the $\mathrm{N}$ treatment was the earliest to reach the terminal point, followed by the $\mathrm{P}$ treatment, $\mathrm{K}$ treatment, and normal nutrient supply.

3.2.3. Development of Leaf Chlorosis in Response to NPK Deficiencies. Based on the above analysis, compared to the 1st and 2nd fully expanded leaves, the 3rd fully expanded leaf showed more obvious responses in terms of morphology and colour. Accordingly, the 3rd fully expanded leaf was further applied to reveal the process of leaf chlorosis.

As observed in Figure 6, the development of leaf chlorosis showed an overall tendency of "slow-fast-slow" in all treatments. Lower nutrient supply appeared to result in higher percentages of chlorosis and faster chlorosis development (Figures 6(a)-6(c)). Furthermore, the comparison among NPK treatments (Figure 6(d)) indicated that leaf chlorosis resulting from $\mathrm{N}$ deficiency developed the most quickly, followed by $\mathrm{P}$ deficiency and then $\mathrm{K}$ deficiency.

As can be seen, in morphological or in colour characteristics, the leaf dynamics of the three fully expanded leaves showed distinct changes in the different nutrient supplies. However, the dynamic changes in leaf characteristics were more significant in older leaves than in younger leaves, and colour changes were more obvious than morphological changes. Moreover, dynamic changes in the local feature (the chlorotic part in the 3rd fully expanded leaf) also differed significantly among the nutrient supply conditions. The responses of the three fully expanded leaves to NPK deficiency suggested that dynamic characteristics of leaf colour and local feature in the older fully expanded leaves could be effective indicators for nutrition diagnosis. 


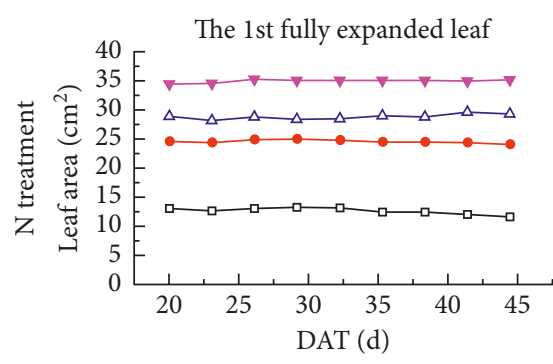

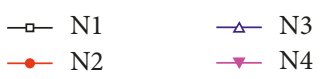

(a)
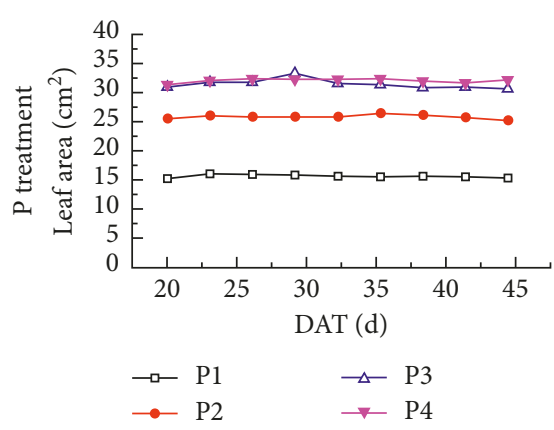

(d)
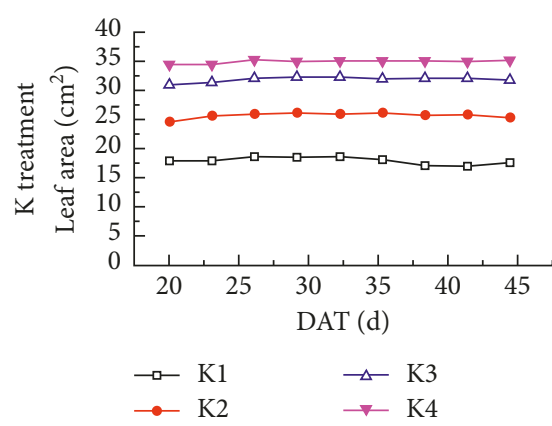

(g)

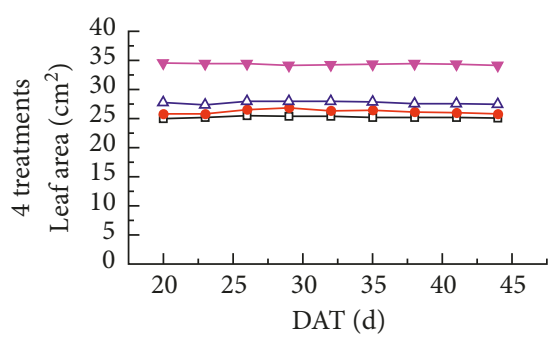

$\neg N$ treatment $\rightarrow-K$ treatment $\rightarrow$ P treatment $\rightarrow$ Normal

(j)
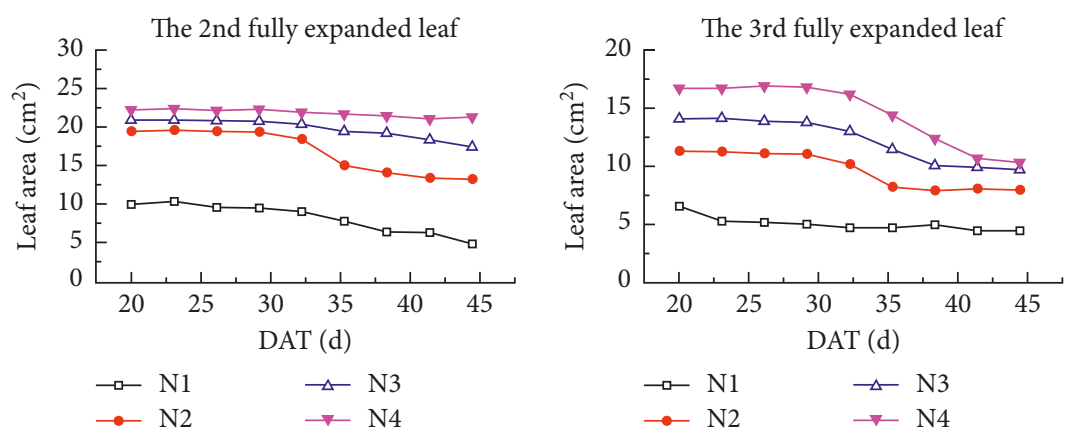

(b)
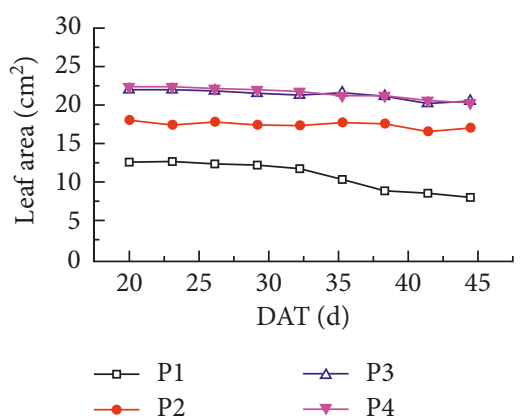

(e)
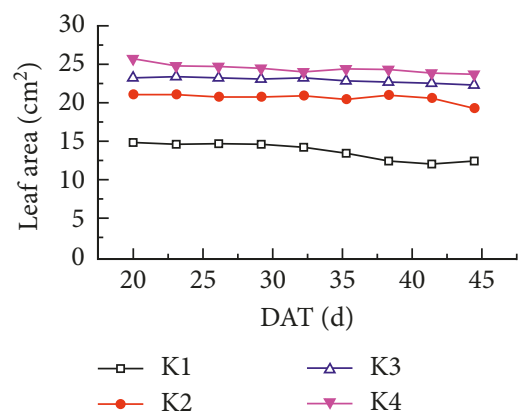

(h)

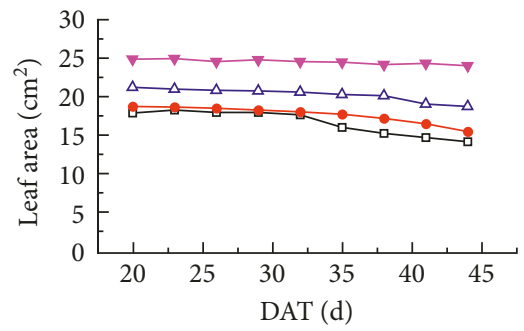

$\neg-N$ treatment $\rightarrow-K$ treatment

$\rightarrow$ P treatment $\rightarrow$ Normal

(k)

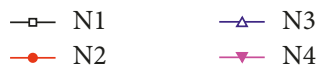

(c)

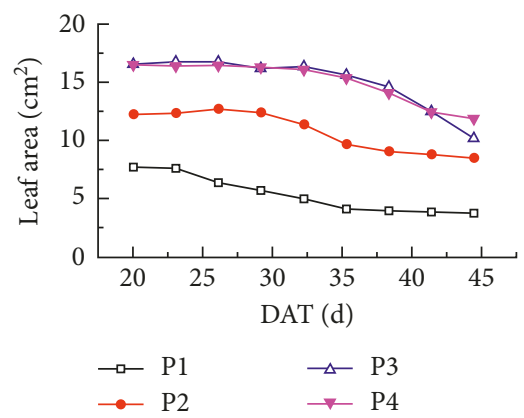

(f)

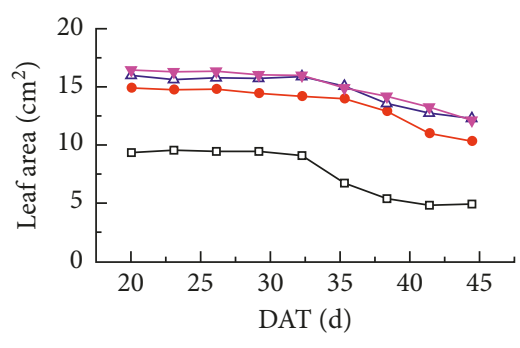

$\rightarrow \mathrm{K} 1 \quad \rightarrow \mathrm{K} 3$

(i)

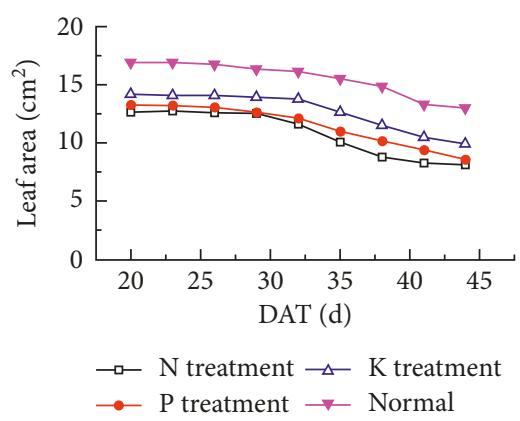

(1)

Figure 4: Leaf area responses of the first three fully expanded leaves to different nutrient supplies: (a, b, c) N treatment, (d, e, f) P treatment, $(\mathrm{g}, \mathrm{h}, \mathrm{i}) \mathrm{K}$ treatment, and $(\mathrm{j}, \mathrm{k}, \mathrm{l})$ four treatments (average value of the four nutrition levels in each treatment). The three columns from the left to right present colour variations in the 1st, 2nd, and 3rd fully expanded leaves, respectively. DAT: day after transplantation.

3.3. Potential Evaluation of Dynamic Indices in Identification of Different Kinds and Levels of Nutrient Deficiency. As described above, distinctions among different nutrient supplies were observed in both morphological and colour dynamics; thus, it is helpful to quantify these distinctions for nutrition diagnosis. As indicated in previous studies [1, 12, 14], there are various kinds of indices that could effectively reveal the plant nutrition status. However, they show different levels of effectiveness in the identification of different kinds and different levels of nutrient deficiency because of the different 

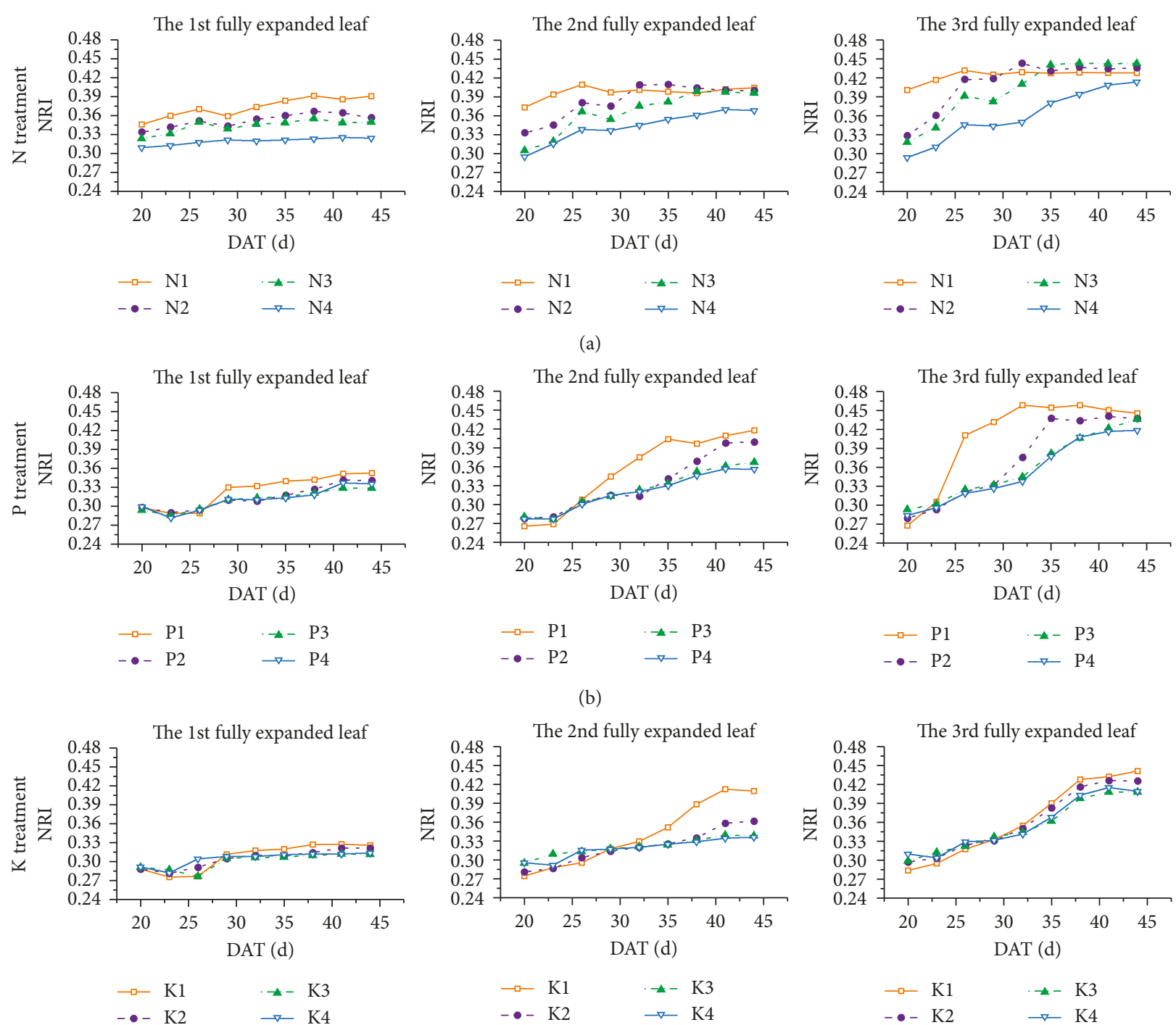

(b)
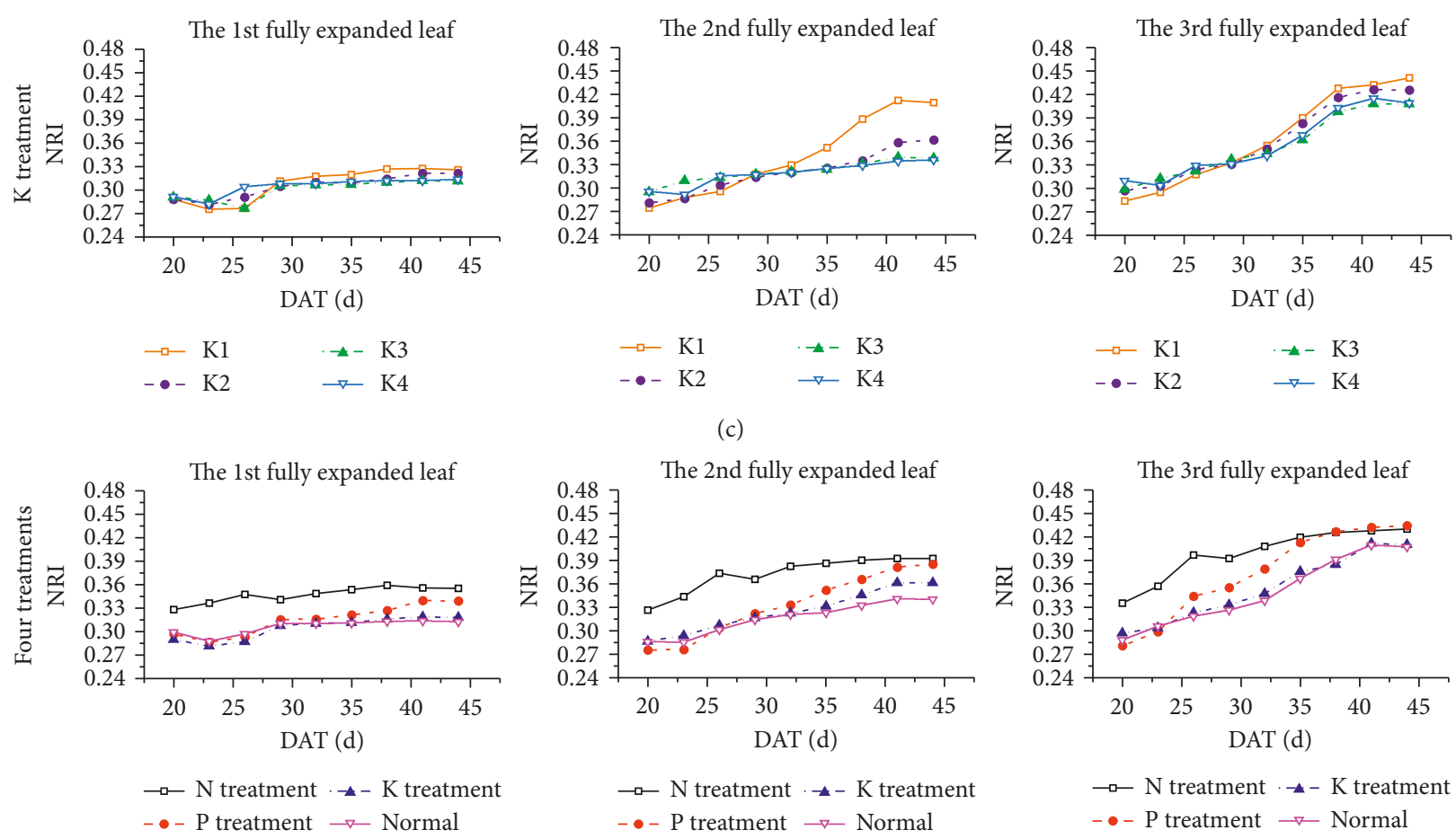

(d)

FIGURE 5: Leaf colour responses of the three fully expanded leaves to different nutrient supplies: (a) N treatment, (b) P treatment, (c) K treatment, and (d) the overall changes in the N, P, K, and normal treatments (average values of the four nutrition levels in each treatment). DAT: day after transplantation.

identification mechanisms. For this reason, we selected 14 indices that have been widely used in nutrition diagnosis to quantify leaf morphological and colour dynamics, and we further evaluated their effectiveness in diagnosis. Thus, a few of the most effective indices could be selected based on the results of this evaluation, thereby reducing the computational complexity and improving the diagnostic effect. 

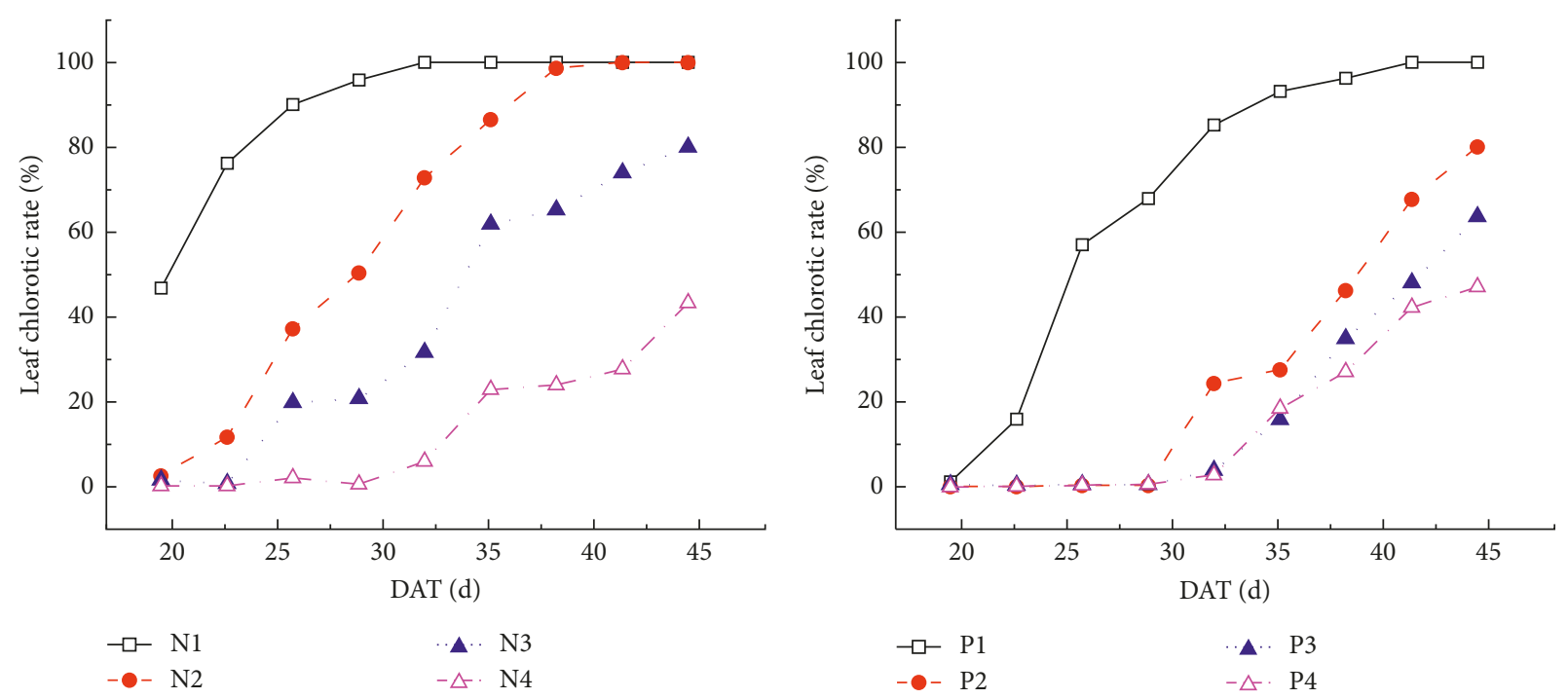

(a)

(b)
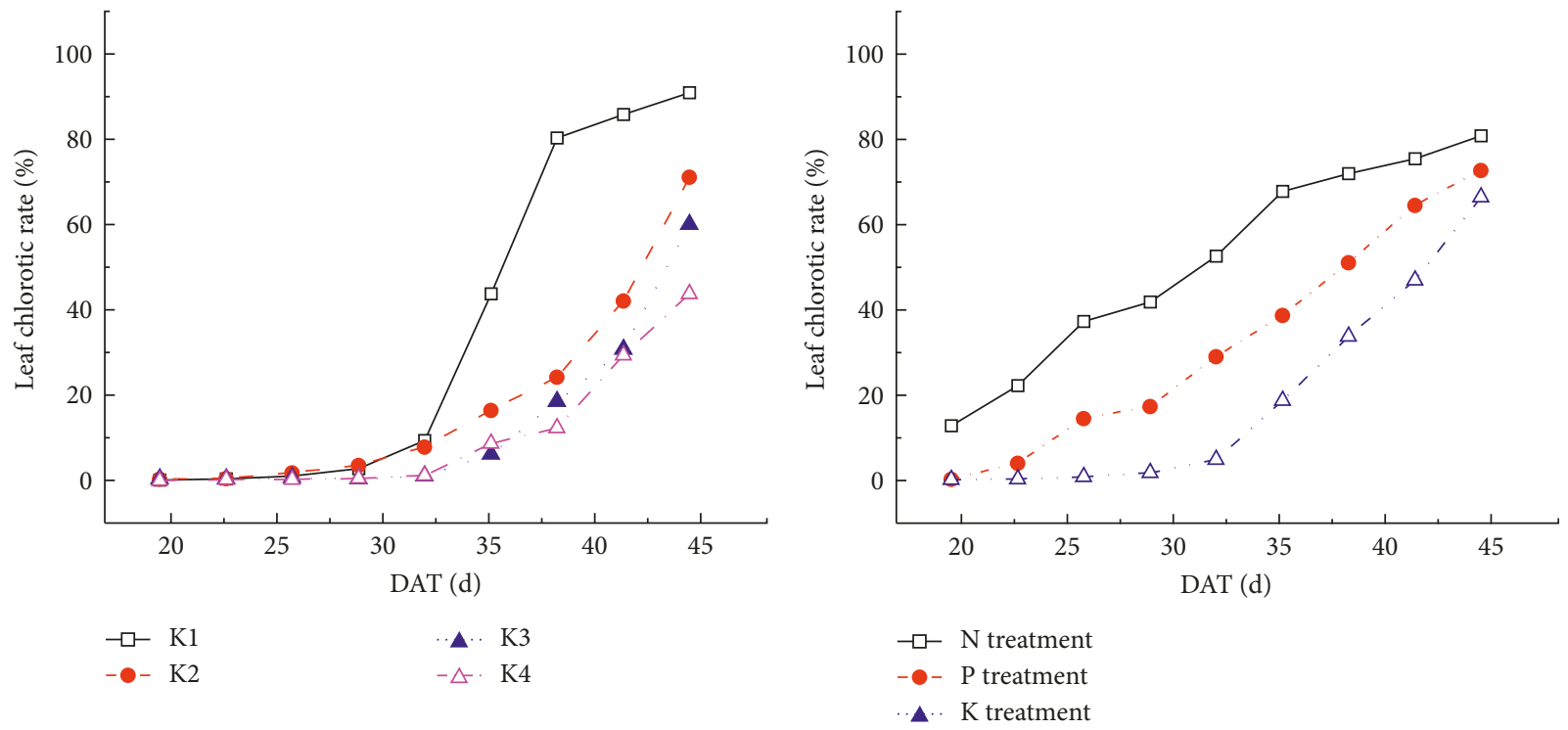

(c)

(d)

Figure 6: Development of the chlorotic part with different nutrient supplies: (a) N treatment, (b) P treatment, (c) K treatment, and (d) the overall changes in the N, P, K, and normal treatments (average values of the four nutrition levels in each treatment). DAT: day after transplantation.

3.3.1. Potential for Identification of Different Types of $\mathrm{Nu}$ trient Deficiencies. Figure 7 shows the MIV results based on identification of four types of treatments $(\mathrm{N}, \mathrm{P}, \mathrm{K}$, and normal). In data sets for the 1 st incomplete leaf, a decreasing trend of the MIV was observed from P1 to P7, which indicates that the dynamic indices calculated at the leaf extension stage were highly distinctive among the four treatments. Furthermore, it also implied that the optimal indices were mainly calculated from leaf morphological features (LP, LL, LA, and LW), especially in the P1 data set.

In data sets of fully expanded leaves (the 1st, 2nd, and 3 rd leaves), the 3 rd leaf achieved a higher MIV than the 2 nd fully expanded leaf, and the 1st fully expanded leaf performed poorly in potential evaluation. A similar changing trend of "low-high-low" from P1 to P7 was found in the 2nd and 3rd leaves, and the colour indices (especially the R, $\mathrm{I}_{\mathrm{KAW}}$, ExG, and ExGR) performed better than the morphological indices. Additionally, only CLA among the morphological indices produced satisfactory results.

Furthermore, Figure 7 also shows that indices of the 1st incomplete leaf had a higher MIV in P1 and P2, while fully expanded leaves (especially the 3rd leaf) had a higher MIV in P3-P7.

3.3.2. Potential for Identification of Different Levels of $\mathrm{Nu}$ trient Deficiencies. The above results indicated that the dynamic indices calculated from the 1 st incomplete leaf and the 3rd fully expanded leaf showed greater potential for use in identification. Therefore, these two leaves were further 


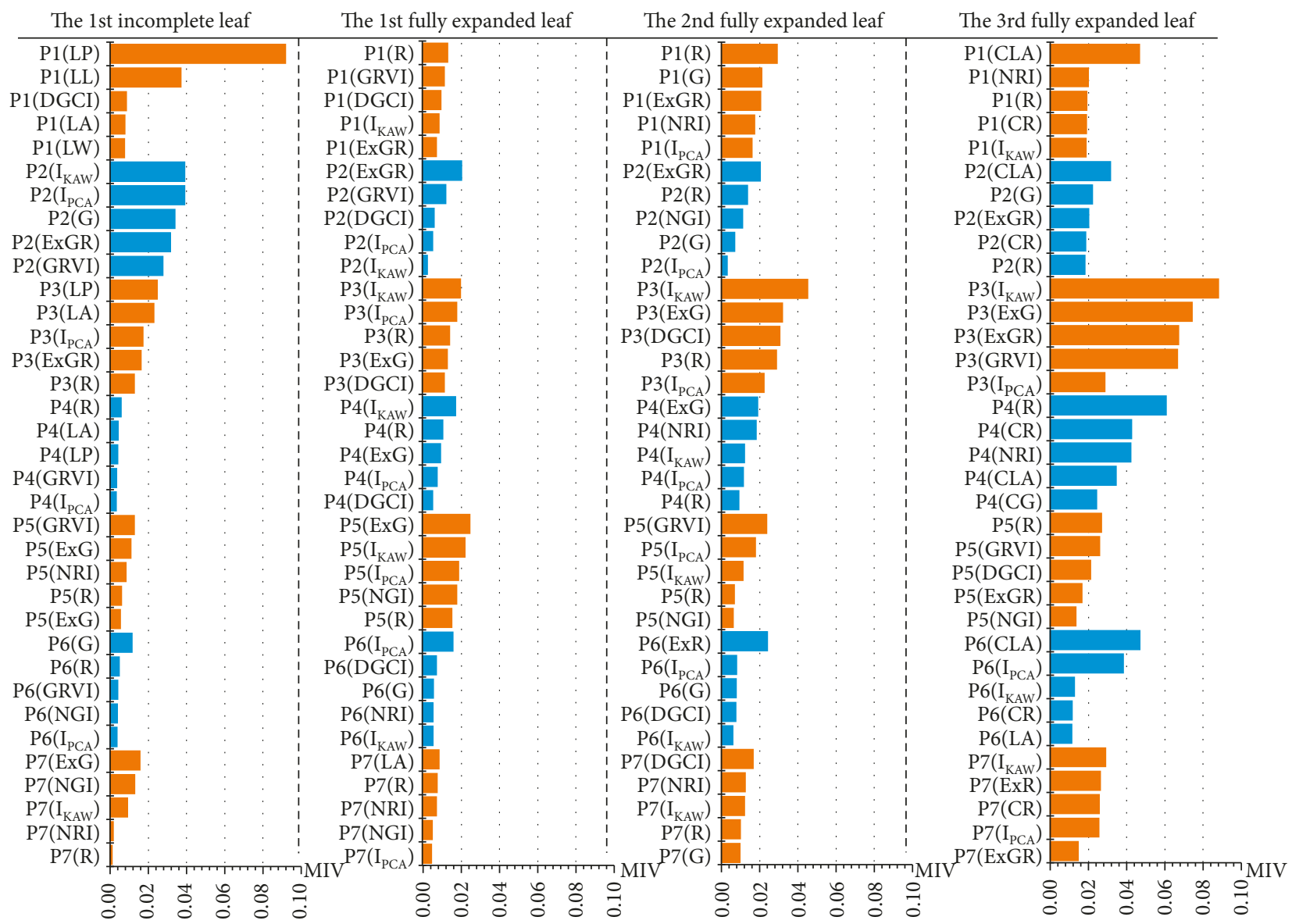

Figure 7: Top five indices selected based on the absolute value of MIV in each data set.

applied in potential evaluation of identifying different levels of nutrient deficiency.

As depicted in Figure 8, the 1st incomplete leaf showed a higher MIV at the early stage (leaf extension stage) and the 3rd fully expanded leaf achieved a higher MIV at a later stage (leaf chlorosis stage). However, the optimal indices (those that produced a higher MIV) differed among NPK treatments. For identifying different levels of $\mathrm{N}$ deficiency (Figures 8(a) and 8(b)), the optimal indices were LA, LP, NGI, $I_{K A W}, E x G$, and NRI from the 1st incomplete leaf and were NGI, $I_{K A W}, I_{P C A}, C R$, and ExG from the 3 rd fully expanded leaf. For identifying different levels of $\mathrm{P}$ deficiency (Figures 8(c) and 8(d)), the optimal indices were LL, LW,

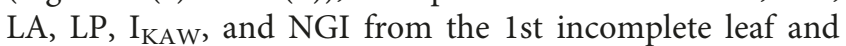

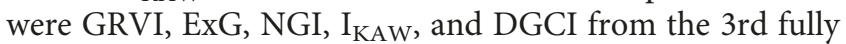
expanded leaf. For identifying different levels of K deficiency (Figures 8(e) and 8(f)), the optimal indices were LA, LP, LL, NRI, and GRVI from the 1st incomplete leaf and were CLA, NGI, NRI, $I_{P C A}$, and R from the 3rd fully expanded leaf.

\section{Discussion}

\subsection{Dynamic Responses of Leaf Morphology and Colour to NPK Deficiency}

4.1.1. Leaf Morphology. As the irreplaceable nutrients in plant growth, deficiencies in NPK nutrition inhibit leaf extension and accelerate leaf wilt. Consequently, higher nutrient supply generates bigger leaf area, faster leaf extension rate (Figure 2), and slower senescent rate (Figures 4 and 6). Moreover, it was stated in the previous paper [33] that $\mathrm{P}$ and $\mathrm{K}$ deficiencies have a secondary influence on leaf growth when compared with $\mathrm{N}$ deficiency. In this paper, the leaf morphological responses to NPK deficiencies confirmed these findings and further showed that $\mathrm{N}$ deficiency has the greatest influence on leaf growth, followed by $\mathrm{P}$ deficiency and then by $\mathrm{K}$ deficiency.

4.1.2. Leaf Colour. As reported in previous studies, the NRI had a negative correlation with the leaf $\mathrm{N}$ content, which suggests that a greener leaf results in a smaller NRI [26, 27]. Therefore, the NRI showed a declining trend because rice leaves become greener during leaf extension (Figure 3). Likewise, fully expanded leaves showed an increasing trend of NRI because of leaf chlorosis (Figure 5). Temporal dynamics of NRI not only showed the colour changes during leaf extension and chlorosis but also revealed the effects of different nutrient supplies on leaf growth. For instance, colour variations of the three fully expanded leaves reached the terminal point earlier under lower nutrient supply (Figure 5), which indicated that the greater the influence of nutrient deficiency was, the faster the development of leaf chlorosis. In this sense, the influence of NPK deficiencies on 

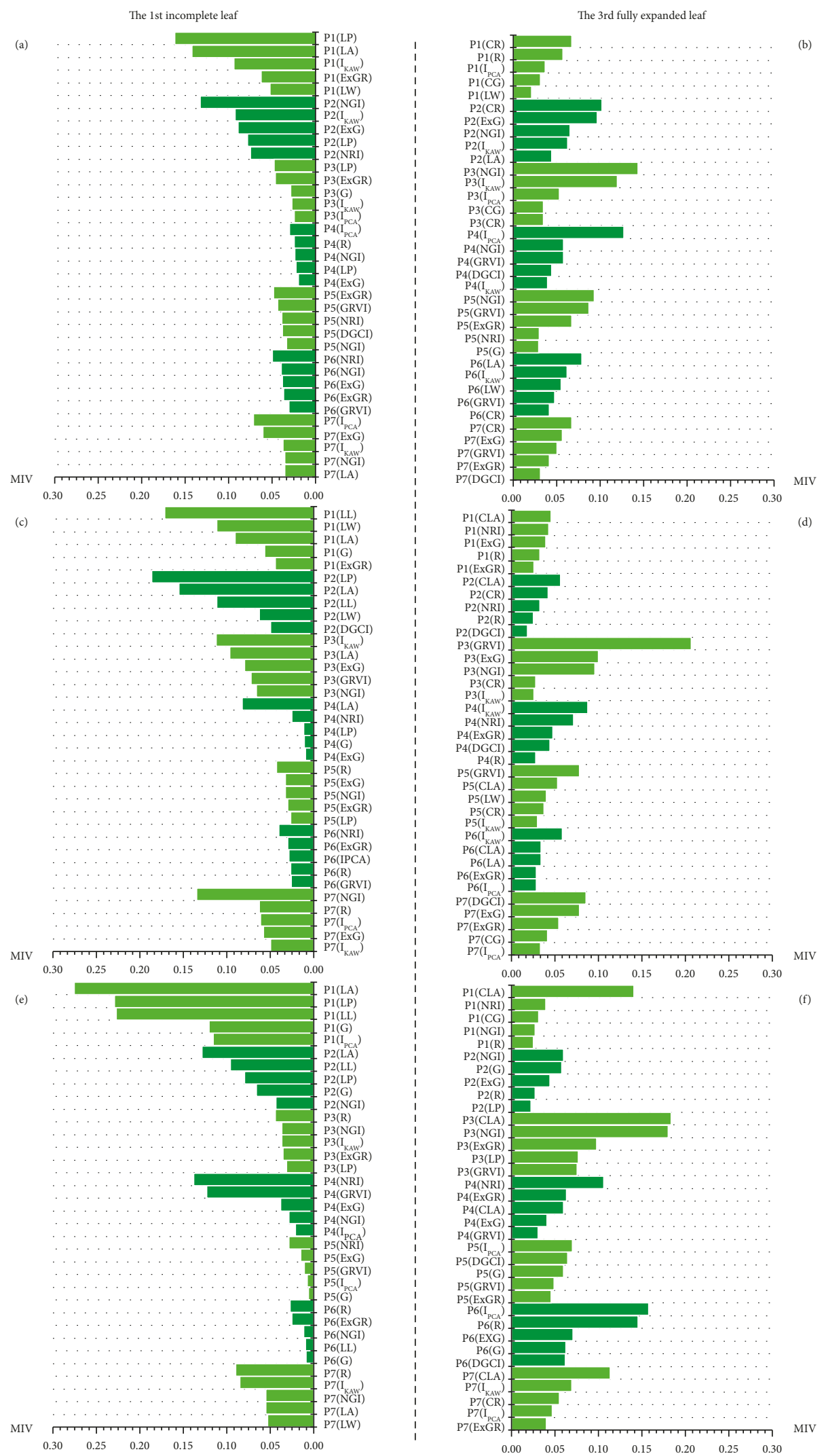

Figure 8: The top five indices selected based on the absolute value of MIV in each data set. (a, b) N treatment, (c, d) P treatment, and (e, f) K treatment. 
leaf growth from big to small in proper order are $\mathrm{N}$ deficiency, $\mathrm{P}$ deficiency and $\mathrm{K}$ deficiency, which is consistent with the conclusion drawn from morphological dynamics.

\subsection{Effectiveness of Dynamic Indices in Nutrition Diagnosis.} In previous studies, the 3rd fully expanded leaf was considered the most ideal leaf in plant nutrition diagnosis $[15,19]$. However, temporal dynamics of leaf morphology and colour suggested that both the 1st incomplete leaf and the 3rd fully expanded leaf conveyed valuable information for nutrition diagnosis (Figures 2-6). Furthermore, the potential evaluation provided further evidence regarding the effectiveness of dynamic indices in diagnosis, revealing the optimal indices, diagnostic times and corresponding leaf positions.

From the perspective of dynamics, the more obvious the dynamics in rice leaf, the larger the distinctions among different treatments can be. During the life cycle of the rice leaf, significant dynamics mainly exist during the stages of leaf extension and senescence. Thus, when exposed to NPK deficiencies, the leaf extension stage and chlorotic stage would be the optimal times for diagnosis. Therefore, the 1st incomplete leaf and the 3rd fully expanded leaf, which provided information about leaf extension and chlorosis, respectively, would be the optimal leaf positions for identifications based on dynamic characteristics. Accordingly, the 1st incomplete leaf achieved higher MIV at the extension stage, and the 3rd fully expanded leaf showed a higher MIV at the chlorotic stage (Figures 7 and 8). Moreover, these results also implied that the identification mechanisms of using the 1st incomplete leaf and the 3rd fully expanded leaf are, respectively, based on the dynamics of leaf extension and chlorosis. Morphological dynamics are the most significant changes during leaf extension, and colour dynamics are the most significant variations during leaf chlorosis. Consequently, morphological indices of the 1st incomplete leaf and colour indices of the 3rd fully expanded leaf would be the optimal indices for identification.

\subsection{Application of Dynamic Analysis to Future Work. By} using nondestructive technology, a time series of plant images can be acquired to reveal phenotypic responses to environmental stress $[22,23]$, such as the distinct responses of leaf morphology and colour to NPK deficiencies in this paper, helping us to further explore the mechanisms of plant growth.

Moreover, the 1st incomplete leaf has seldom been used in nutrition diagnosis because of its instability. However, the dynamic analysis and potential evaluation collectively revealed that the dynamic characteristics of the 1st incomplete leaf are valuable for diagnosis. Therefore, the dynamic indices of the 1st incomplete leaf can be further used in the establishment of diagnostic models, thus improving the effectiveness of early diagnosis.

Furthermore, the dynamic nature of typical symptoms, such as the development of brown necrotic spots on rice leaves caused by $\mathrm{K}$ deficiency, is important for the analysis of plant growth mechanisms and the exploration of sensitive characteristics for identification.

\section{Conclusions}

In this study, from expanding leaf (the first incomplete leaf) to fully expanded leaves and from entire leaf characteristics to local features, we analysed the dynamic responses of leaf morphology and colour to different NPK nutrition supplies. Moreover, the potential evaluation further revealed the effective indices and the optimal time for diagnosis. The major conclusions drawn from this study were as follows:

(a) Leaves with lower nutrient supply showed slower leaf extension and faster development of leaf chlorosis. Moreover, dynamics of leaf morphology and colour collectively suggest that $\mathrm{N}$ deficiency has the greatest influence on leaf extension and senescence, followed by $\mathrm{P}$ deficiency and then by K deficiency.

(b) In the 1st incomplete leaf, the dynamic indices calculated from leaf morphology (LA, LP, LL, and LW) at the leaf extension stage would be ideal indices to identify nutrient deficiency.

(c) In fully expanded leaves, the dynamic indices calculated from leaf colour (such as R, NGI, $\mathrm{I}_{\mathrm{KAW}}, \mathrm{ExG}$, and $\mathrm{I}_{\mathrm{PCA}}$ ) and chlorotic part (CLA, CR, and CG) at the leaf chlorosis stage would also be effective indices for identification.

\section{Data Availability}

The authors confirm that all data underlying the findings are fully available without restriction, and could be replicated the study's findings (https://share.weiyun.com/ bc7d26042a41d47029abc57169369d0f) or from the corresponding author upon request.

\section{Conflicts of Interest}

No conflicts of interest exit in the submission of this manuscript, and the manuscript is approved by all authors for publication.

\section{Acknowledgments}

This study was financed by grants from the National Natural Science Foundation of China (Grant no. 31172023) and Zhejiang Postdoctoral Sustentation Fund of China (Grant no. BSH1502132). The author thanks Enyan Zhu, Lingyan Huang, Ruowei Jiang, Yue Su, and Ziran Ye for the help in acquiring rice leaf images and Melanie Valerie Weston for polishing the language of this article.

\section{References}

[1] L. Chen, Rice Nutrition Identification and Diagnosis Based on Machine Vision Technology, Zhejiang University, Hangzhou, China, 2014.

[2] S. Oyedeji, D. A. Animasaun, A. A. Bello, and O. O. Agboola, "Effect of NPK and poultry manure on growth, yield, and proximate composition of three amaranths," Journal of Botany, vol. 2014, Article ID 828750, 6 pages, 2014.

[3] S. Ji-Yong, Z. Xiao-Bo, Z. Jie-Wen et al., "Nondestructive diagnostics of nitrogen deficiency by cucumber leaf chlorophyll 
distribution map based on near infrared hyperspectral imaging," Scientia Horticulturae, vol. 138, pp. 190-197, 2012.

[4] Y. L. Liu, L. Qiang, S. L. He, S. L. Yi, and X. F. Liu, "Prediction of nitrogen and phosphorus contents in citrus leaves based on hyper spectral imaging," International Journal of Agricultural and Biological Engineering, vol. 8, no. 2, pp. 80-88, 2015.

[5] S. Jun, J. Xiaming, M. Hanping et al., "Detection of nitrogen content in lettuce leaves based on spectroscopy and texture using hyperspectral imaging technology," Transactions from the Chinese Society of Agricultural Engineering, vol. 10, pp. 167-173, 2014.

[6] T. Rapaport, U. Hochberg, M. Shoshany, A. Karnieli, and S. Rachmilevitch, "Combining leaf physiology, hyperspectral imaging and partial least squares-regression (PLS-R) for grapevine water status assessment," ISPRS Journal of Photogrammetry and Remote Sensing, vol. 109, pp. 88-97, 2015.

[7] Y. Kim, D. M. Glenn, J. Park, H. K. Ngugi, and B. L. Lehman, "Hyperspectral image analysis for water stress detection of apple trees," Computers and Electronics in Agriculture, vol. 77, no. 2, pp. 155-160, 2011.

[8] K. Q. Yu, Y. R. Zhao, X. L. Li, Y. N. Shao, F. Liu, and Y. He, "Hyperspectral imaging for mapping of total nitrogen spatial distribution in pepper plant," PLoS One, vol. 9, no. 12, Article ID e11620512, 2014.

[9] H. Cen, R. Lu, Q. Zhu, and F. Mendoza, "Nondestructive detection of chilling injury in cucumber fruit using hyperspectral imaging with feature selection and supervised classification," Postharvest Biology and Technology, vol. 111, pp. 352-361, 2016.

[10] C. H. Bock, G. H. Poole, P. E. Parker, and T. R. Gottwald, "Plant disease severity estimated visually, by digital photography and image analysis, and by hyperspectral imaging," Critical Reviews in Plant Sciences, vol. 29, no. 2, pp. 59-107, 2010.

[11] Y. Wang, D. Wang, P. Shi, and K. Omasa, "Estimating rice chlorophyll content and leaf nitrogen concentration with a digital still color camera under natural light," Plant Methods, vol. 10, no. 1, pp. 36-46, 2014.

[12] Y. Wang, D. Wang, and G. Zhang, "Nitrogen status diagnosis of rice based on a digital camera," Chinese Agricultural Science Bulletin, vol. 28, no. 24, pp. 111-117, 2012.

[13] Y. Wang, D. Wang, G. Zhang, and J. Wang, "Estimating nitrogen status of rice using the image segmentation of G-R thresholding method," Field Crops Research, vol. 149, pp. 33-39, 2013.

[14] L. Chen, L. Lin, G. Cai et al., "Identification of nitrogen, phosphorus, and potassium deficiencies in rice based on static scanning technology and hierarchical identification method," PLoS One, vol. 9, no. 11, Article ID e11320011, 2014.

[15] Y. Shi, J. Deng, L. Chen, D. Zhang, X. Ding, and K. Wang, "Leaf characteristics extraction of rice under potassium stress based on static scan and spectral segmentation technique," Spectroscopy And Spectral Analysis, vol. 30, no. 1, pp. 214-219, 2010.

[16] X. Liu, K. Zhang, Z. Zhang, Q. Cao, Z. Lv, and Z. Yuan, "Canopy chlorophyll density based index for estimating nitrogen status and predicting grain yield in rice," Frontiers in Plant Science, vol. 8, no. 10, pp. 1-12, 2017.

[17] Z. Yuan, S. T. Ata-ul-karim, Q. Cao, Z. Lu, W. Cao, and Y. Zhu, "Field crops research indicators for diagnosing nitrogen status of rice based on chlorophyll meter readings," Field Crops Research, vol. 185, pp. 12-20, 2016.

[18] M. M. Saberioon, M. S. M. Amin, A. R. Anuar, A. Gholizadeh, A. Wayayok, and S. Khairunniza-Bejo, "Assessment of rice leaf chlorophyll content using visible bands at different growth stages at both the leaf and canopy scale," International Journal of Applied Earth Observation and Geoinformation, vol. 32, pp. 35-45, 2014.

[19] L. S. Chen and K. Wang, "Diagnosing of rice nitrogen stress based on static scanning technology and image information extraction," Journal of Soil Science and Plant Nutrition, vol. 14, pp. 382-393, 2014.

[20] Y. Shi, Rice Nutrition Diagnosis and Modeling Based on Digital Image, Zhejiang University, Hangzhou, China, 2011.

[21] K. Mengel and E. A. Kirkby, Principles of Plant Nutrition, International Potash Institute, Horgen, Switzerland, 1987.

[22] R. Poiré, V. Chochois, X. R. R. Sirault, J. P. Vogel, and M. Watt, "Digital imaging approaches for phenotyping whole plant nitrogen and phosphorus response in Brachypodium distachyon," Journal of Integrative Plant Biology, vol. 56, no. 8, pp. 781-796, 2014.

[23] E. H. Neilson, A. M. Edwards, C. K. Blomstedt, B. Berger, B. L. Moller, and R. M. Gleadow, "Utilization of a highthroughput shoot imaging system to examine the dynamic phenotypic responses of a $\mathrm{C} 4$ cereal crop plant to nitrogen and water deficiency over time," Journal of Experimental Botany, vol. 66, no. 7, pp. 1817-1832, 2015.

[24] Y. Ge, G. Bai, V. Stoerger, and J. C. Schnable, "Temporal dynamics of maize plant growth, water use, and leaf water content using automated high throughput RGB and hyperspectral imaging," Computers and Electronics in Agriculture, vol. 127, pp. 625-632, 2016.

[25] Z. Yong-hui, T. Liang, L. I. U. Xiao-jun, L. I. U. Lei-lei, C. A. O. Wei-xing, and Z. H. U. Yan, "Modeling dynamics of leaf color based on RGB value in rice," Journal of Integrative Agriculture, vol. 13, no. 4, pp. 749-759, 2014.

[26] G. Qin, D. Jinson, L. Cha, S. Yuanyuan, W. Ke, and S. Zhangquan, "Diagnosis of rice nitrogen nutrition based on spectral and shape characteristics of scanning leaves," Transactions of the Chinese Society of Agricultural Machinery, vol. 43, no. 8, pp. 170-174, 2012.

[27] L. I. Lan-tao, Z. Meng, R. E. N. Tao et al., "Diagnosis of N nutrition of rice using digital image processing technique," Journal of Plant Nutrition and Fertilization, vol. 21, no. 1, pp. 259-268, 2015.

[28] Y. Wang, D. Wang, G. Zhang et al., "Digital camera-based image segmentation of rice canopy and diagnosis of nitrogen nutrition," Transactions from the Chinese Society of Agricultural Engineering, vol. 28, no. 17, pp. 131-136, 2012.

[29] R. C. Gonzalez and R. E. Woods, Digital Image Processing Using MATLAB, Pearson Education North Asia Limited, Singapore, 2nd edition, 2002.

[30] R. Hunt, Plant Growth Curves: the Functional Approach to Plant Growth Analysis, Edward Arnold, London, UK, 1982.

[31] J. F. Xu, J. Xu, S. Z. Li et al., "Transmission risks of schistosomiasis japonica: extraction from back-propagation artificial neural network and logistic regression model," PLoS Neglected Tropical Diseases, vol. 7, no. 4, article e21233, 2013.

[32] L. Hu, Y. Wei, X. Zhao et al., "Study of screening the effective components of traditional Chinese medicine based on GAANN pattern recognition technique," China Journal of Traditional Chinese Medicine and Pharmacy, vol. 30, no. 1, pp. 274-277, 2015.

[33] T. Ingestad, "Nitrogen stress in birch seedlings," Physiologia Plantarum, vol. 45, no. 1, pp. 149-157, 1979. 

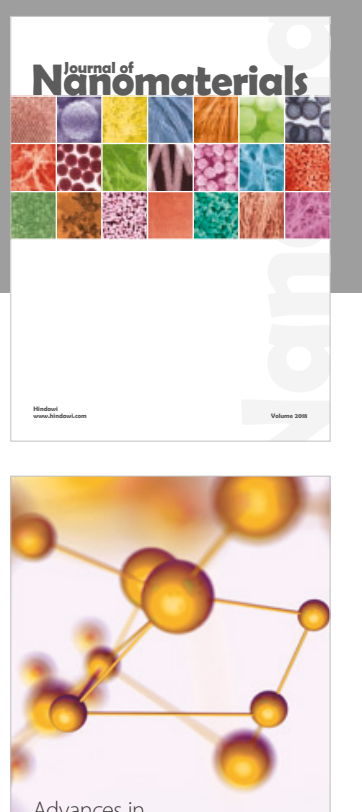

Physical Chemistry
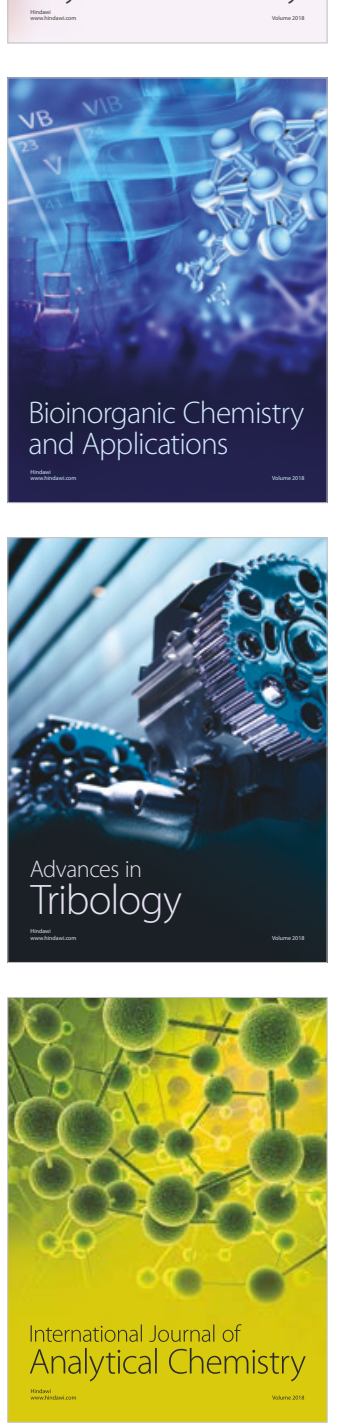

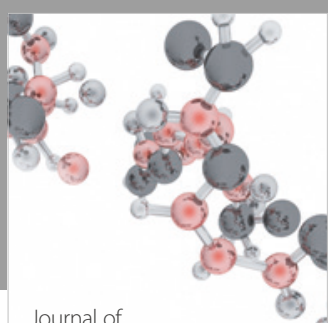

Analytical Methods

in Chemistry

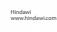

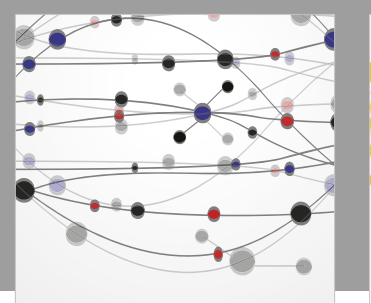

The Scientific World Journal

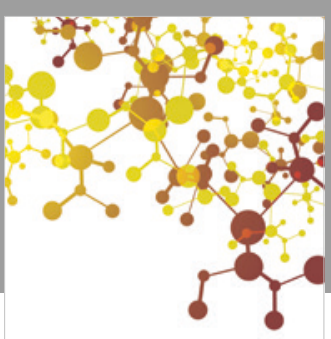

Journal of

Applied Chemistry
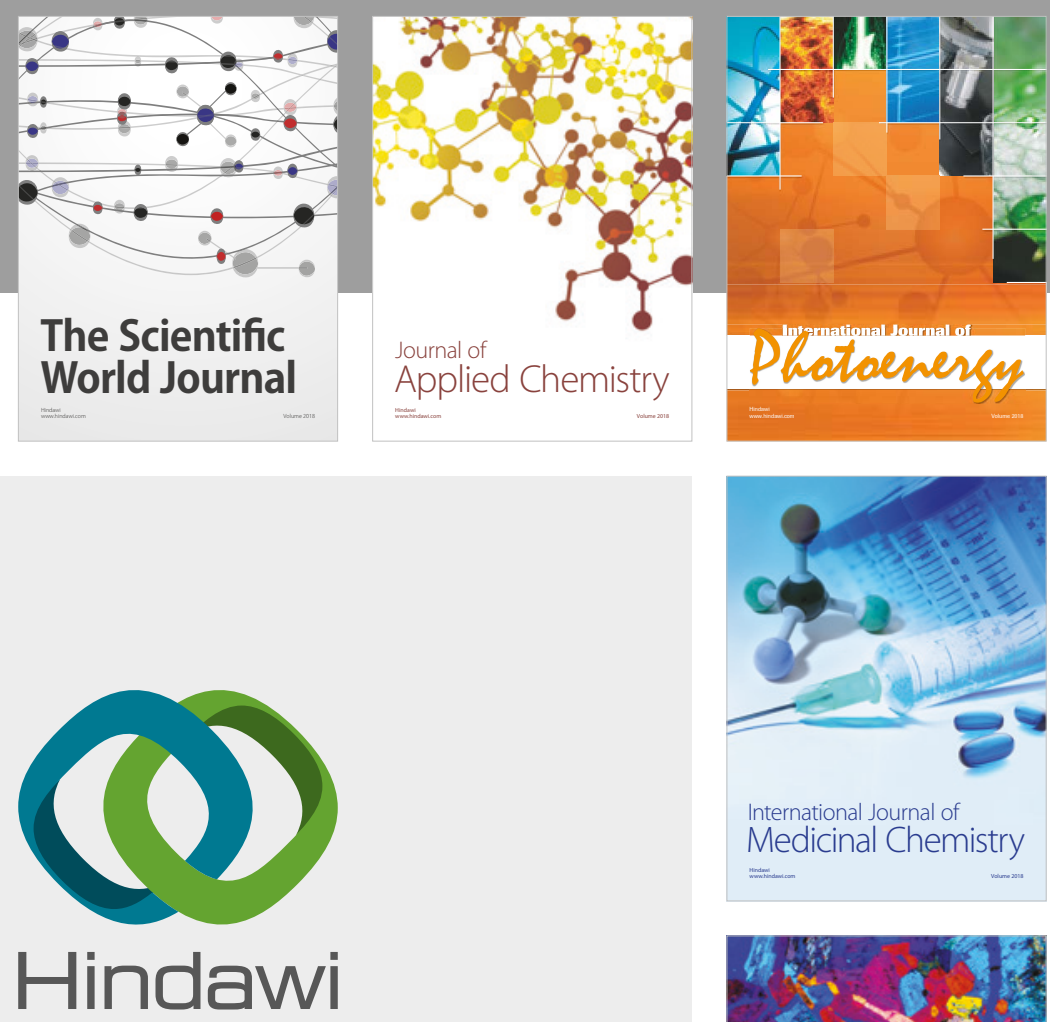

Submit your manuscripts at

www.hindawi.com
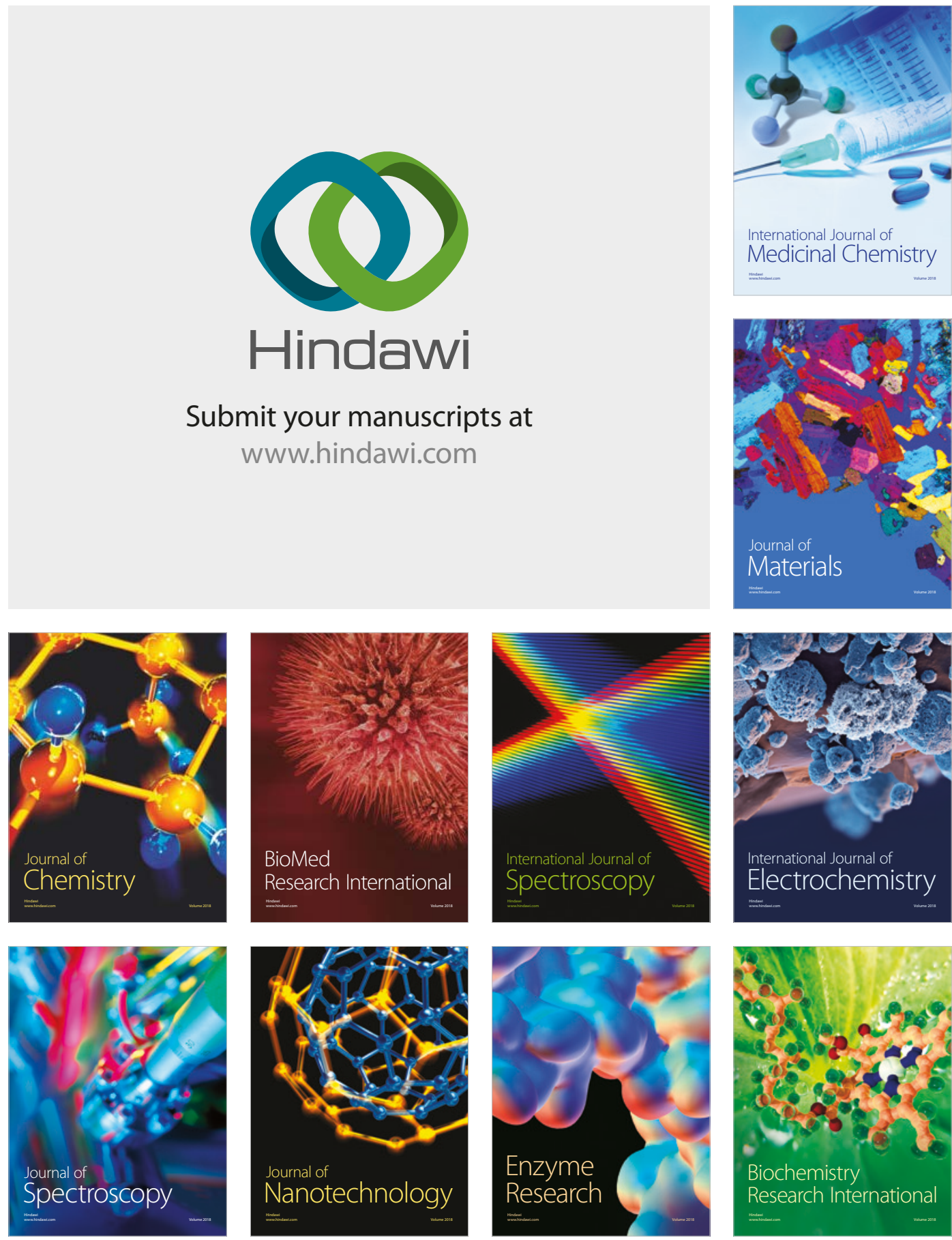
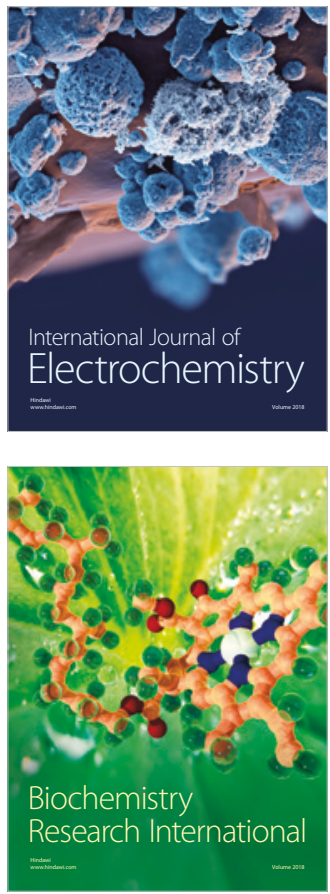